\title{
Retrieval of Surface Solar Radiation Budget under Ice Cloud Sky: Uncertainty Analysis and Parameterization
}

\author{
YING ZHANG \\ Canada Centre for Remote Sensing, Ottawa, Ontario, Canada \\ ZHANQING LI \\ Department of Meteorology and ESSIC, University of Maryland at College Park, College Park, Maryland \\ ANDREAS MACKE \\ Institut fuer Meereskunde, Kiel, Germany
}

(Manuscript received 25 April 2001, in final form 29 April 2002)

\begin{abstract}
This study investigates and accounts for the influence of various ice cloud parameters on the retrieval of the surface solar radiation budget (SSRB) from reflected flux at the top of the atmosphere (TOA). The optical properties of ice clouds depend on ice crystal shape, size distribution, water content, and the vertical profiles of geometric and microphysical structure. As a result, the relationship between the SSRB and TOA-reflected flux for an ice cloud atmosphere is more complex and differs from that for water cloud and cloudless atmospheres. The sensitivities of the relationship between the SSRB and TOA-reflected flux are examined with respect to various ice cloud parameters. Uncertainties in the retrieval of the SSRB due to inadequate knowledge of various ice cloud parameters are evaluated thoroughly. The uncertainty study is concerned with both pure ice clouds and multiphase clouds (ice cloud above water cloud). According to the magnitudes of errors in the SSRB retrieval caused by different input variables, parameterized correction terms were introduced. If the input variables are known accurately, errors in the retrieval of the SSRB under a wide range of ice cloud conditions are expected to diminish substantially, to less than $10 \mathrm{~W} \mathrm{~m}^{-2}$ for $91 \%$ of the simulated ice cloud cases. In comparison, the same accuracy may be attained for only $19 \%$ of the retrievals for the same ice cloud cases using the retrieval algorithm designed for non-ice-cloud conditions.
\end{abstract}

\section{Introduction}

The surface solar radiation budget (SSRB) is a basic climate quantity, which affects considerably the surface heat and moisture budgets as well as biological productivity. The transformation of solar energy into terrestrial radiation, and latent and sensible heat governs most of the dynamic and hydrological processes (Randall et al. 1989; Stephens and Greenwald 1991). In recognition of its significance, numerous ground-based and spaceborne programs have been initiated to monitor the SSRB on both global and local scales. To name a few, there are the ground-based observation networks that include the World Baseline Radiation Network (BSRN; Ohmura et al. 1998), the Atmospheric Radiation Mea-

Corresponding author address: Z. Li, Dept. of Meteorology and ESSIC, 2335 Computer and Space Science Bldg, University of Maryland at College Park, College Park, MD 20742.

E-mail: zli@atmos.umd.edu surement (ARM) program (Stokes and Schwartz 1994), and the U.S. Surface Radiation Budget Network (SURFRAD; Augustine et al. 2000). These ground-based observation systems provide high quality, calibrated, continuous measurements of the SSRB, but suffer from very limited spatial coverage and variable observation quality. To meet the need for validating climate models (Wild et al. 1995; Ward 1995; Barker and Li 1995; Fowler and Randall 1996; Li et al. 1997), several satellite-based global SSRB datasets have been generated from various satellite missions such as the International Satellite Cloud Climatology Program (ISCCP; Bishop and Rossow 1991; Zhang and Rossow 1995; Whitlock et al. 1995), the Earth Radiation Budget Experiment (ERBE; Li and Leighton 1993), and the Clouds and the Earth's Radiant Energy System (CERES; Wielicki et al. 1996). In addition to providing a global dataset, satellite data have also been used to generate regional SSRB products (Chou and Zhao 1997).

Note that these SSRB products were not directly mea- 
sured by satellite, but inferred from the top of the atmosphere (TOA) reflected radiances using inversion algorithms (Gautier et al. 1980; Pinker and Laszlo 1992; Li et al. 1993; Pinker et al. 1995; Zhang and Rossow 1995). While the algorithms capture the essence of radiative transfer, some details of radiative processes were either left out or simplified for parameterization. The simplification is a contributing factor to some of the discrepancies between observed and estimated SSRB (Li et al. 1995; Whitlock et al. 1995). In the development of SSRB inversion algorithms, emphasis has been placed on liquid water clouds and clear-sky cases. Little or no account has been given to ice clouds, and the magnitude of uncertainties in the estimation of SSRB under ice cloud conditions remains unclear. The Global Energy and Water Cycle Experiment (GEWEX) evolved to the CERES/ARM/(GEWEX) Experiment (CAGEX; Charlock and Alberta 1996); the results of which showed that the bias in their SSRB retrievals for both water and ice clouds is about $40 \mathrm{~W} \mathrm{~m}^{-2}$ obtained from a state of the art radiative transfer model (Fu and Liou 1993). Here, inputs of atmospheric sounding, measured aerosol, and satellite-retrieved cloud data are used, with cloud particle size assumed. Ice clouds, which cover about $60 \%$ of the globe, possess microphysical and optical properties that are far more complicated than those of water clouds, due primarily to the nonsphericity of the ice crystals. The radiative properties of ice clouds depend on ice crystal shape and size distribution, water content, and its vertical structure (Liou and Coleman 1980; Macke et al. 1996; Mishchenko et al. 1996; Zhang et al. 1999). Ice crystal shape varies significantly with crystal size and location in cloud, and evolves during the lifetime of a cloud cell (Heymsfield et al. 1998). For modeling solar radiative transfer, Macke et al. (1996) categorized cloud ice crystals into three major shapes: solid hexagonal columns, solid hexagonal plates, and complex shaped polycrystals. Moreover, the vertical profile of ice clouds is different from that of water clouds. Due to gravitational sedimentation, the mean ice particle size decreases with increasing altitude (Heymsfield and Platt 1984). Ice clouds are usually much higher in the atmosphere than water clouds and vary over a large range of altitude. Schmetz (1993) pointed out that cloud-top height has a larger impact on net solar flux at the TOA than at the earth's surface, especially for large cloud optical depths, implying that cloud-top height also has an impact on the retrieval. In summary, the radiative properties of ice clouds and their impact on TOA and surface solar fluxes are unique and significant enough to warrant a special investigation. Furthermore, it is envisioned that more radiative properties of ice clouds will be made available in the near future from the new generation of satellite sensors, such as a 94-GHz radar on board the CloudSat and the Moderate Resolution Imaging Spectroradiometer (MODIS) on
Terra. At present, significant progress has been made in retrieving basic ice cloud properties such as the optical depth and effective size (Ou et al. 1999).

Li et al. (1993) derived a linear relationship for the fast retrieval of the SSRB from reflected solar radiation at the TOA, with the intercept and the slope parameterized as functions of solar zenith angle (SZA) and precipitable water. While separate relationships were derived for clear sky and for four different cloud types (labelled St II, Sc II, Cu, and Ci), a lone cirrus cloud with fixed optical properties was assumed. They found that for more than $90 \%$ of clear- and cloudy-sky cases, the estimated SSRB using the linear relationship was accurate to within $10 \mathrm{~W} \mathrm{~m}^{-2}$ of those simulated by a detailed radiative transfer model (Li et al. 1993). Errors larger than $20 \mathrm{~W} \mathrm{~m}^{-2}$ corresponded partially to cirrus cloud cases. Such errors may be reduced using a dedicated retrieving algorithm and new ice information to be extracted from future advanced active and passive spaceborne sensors.

In this study, a comprehensive investigation is conducted to first test the sensitivities of the SSRB and TOA-reflected flux and their relationship to various ice cloud parameters, and then to account for those parameters that have significant influence on the retrieval of the SSRB. The following section describes the models used for radiative transfer calculation and for determining the optical properties of ice clouds. Section 3 presents the results of sensitivity tests and examines possible sources and magnitudes of uncertainties in the retrieval of the SSRB under ice and mixed-phase cloudy conditions. Parameterized corrections are introduced in section 4 to account explicitly for the effects of icecloud parameters based on model calculations. A summary is given in section 5 .

\section{Radiative transfer models and calculations}

The $\mathrm{Fu}-\mathrm{Liou} \delta$-four-stream radiative transfer model (Fu and Liou 1993; Fu 1996) is used, comprising 429 spectral bands from 0.22 to $22 \mu \mathrm{m}$ and 32 atmospheric layers with a resolution as fine as $1 \mathrm{~km}$ in the troposphere and coarser at higher altitudes. The radiative properties of atmospheric gases (water vapor, $\mathrm{CO}_{2}, \mathrm{O}_{3}$, $\mathrm{O}_{2}$ ) are calculated with Moderate Resolution Atmospheric Radiance and Transmission Model Version 3.5 (MODTRAN-3.5), which also provides aerosol parameters. The vertical profiles of aerosol concentration (in four layers: 0-2, 2-10, 10-30, 30-100 km) are specified according to atmospheric visibility, season and aerosol type (e.g., rural, urban, maritime, and fog type). A set of spectral surface albedos from CERES/Surface and Atmospheric Radiation Budget (SARB) for 17 scene types, listed in Table 1, are used covering six bands ranging from 0.2 to $4.0 \mu \mathrm{m}$. The albedo values vary with SZA (Briegleb et al. 1986).

Parameterizations describing the relationship between ice cloud radiative characteristics (extinction coeffi- 
TABLE 1. Surface scene types used and their broadband albedos (data from CERES/SARB).

\begin{tabular}{clc}
\hline \hline $\begin{array}{c}\text { Scene type } \\
\text { number }\end{array}$ & \multicolumn{1}{c}{ Scene type } & Broadband albedo \\
\hline 1 & Evergreen needle forest & 0.1188 \\
2 & Evergreen broad forest & 0.1300 \\
3 & Deciduous needle forest & 0.1188 \\
4 & Deciduous broad forest & 0.1726 \\
5 & Mixed forest & 0.1443 \\
6 & Closed shrubs & 0.2175 \\
7 & Open/shrubs (desert) & 0.2314 \\
8 & Woody savanna & 0.1620 \\
9 & Savanna & 0.1818 \\
10 & Grassland & 0.1841 \\
11 & Wetland & 0.1147 \\
12 & Cropland & 0.1496 \\
13 & Urban & 0.1697 \\
14 & Crop mosaic & 0.1583 \\
15 & Barren/desert & 0.3551 \\
16 & Tundra & 0.1697 \\
17 & Ocean water & 0.0660 \\
\hline
\end{tabular}

cient, asymmetry factor, and single scattering albedo) and microphysical characteristics (particle phase, shape, and size distribution) were developed for this study. As far as radiative transfer is concerned, the microphysics of cloud particles can be approximated by the effective radius $r_{e}$ and water content (Liou 1992). The general definition of $r_{e}$ is given by

$$
r_{e} \propto \frac{\int_{0}^{\infty} V(r) N(r) d r}{\int_{0}^{\infty} A(r) N(r) d r},
$$

where $V(r)$ is volume, $A(r)$ is surface area, and $N(r)$, the number density of cloud particle with a radius of $r$. For water clouds, cloud droplets are considered as spheres so that determination of $r_{e}$ is straightforward and given by the following equation:

$$
r_{e}=\frac{\int_{0}^{\infty} r^{3} N(r) d r}{\int_{0}^{\infty} r^{2} N(r) d r}
$$

For ice crystals, there is no definitive formula to determine $r_{e}$. For column-shaped crystals, Fu (1996) proposed a generalized effective size parameter $D_{\mathrm{ge}}$ to describe the microphysical features of ice clouds:

$$
D_{\mathrm{ge}}=\frac{\int_{0}^{\infty} \operatorname{DDLn}(L) d L}{\int_{0}^{\infty}\left[D L+0.433 D^{2}\right] n(L) d L},
$$

where $D$ is the width and $L$ is the length of a column crystal. The term $D D L$ in the numerator is proportional to the volume of a hexagonal crystal and the $(D L+$ $0.433 D^{2}$ ) factor in the denominator is proportional to the surface area. The ice water content (IWC) is given by

$$
\operatorname{IWC}=0.649 \rho_{i} \int_{0}^{\infty} \operatorname{DDLn}(L) d L,
$$

where $\rho_{i}$ is the ice density.

The optical properties of the ice crystals are averaged over 28 ice crystal size distributions and fitted as a polynomial function of $D_{\text {ge }}(\mathrm{Fu} 1996)$. The particle size distributions were derived from in situ aircraft observations made in midlatitude and tropical regions. The values of $D_{\mathrm{ge}}$ and IWC were calculated for each individual particle size distribution, with $D_{\text {ge }}$ ranging from 18.6 to $130.2 \mu \mathrm{m}$ and IWC from $5.5 \times 10^{-4}$ to $0.28 \mathrm{~g}$ $\mathrm{m}^{-3}$ (Fu 1996). Most of the calculations done for this work employed ice crystal optical properties given by $\mathrm{Fu}$ (1996).

The impact of crystal shapes is studied using three other crystal shapes: hexagonal columns, plates, and polycrystals from Macke et al. (1998). The first two shapes are often observed in ice clouds, and the optical characteristics of polycrystals are deemed to be representative of bulk ice crystals (Macke et al. 1998). The ice crystal optical properties (asymmetry factor and single scattering albedo) of these three shapes are computed with a ray tracing method (Macke et al. 1996). For each shape type, 28 ice crystal size distributions given by $\mathrm{Fu}$ (1996) were used to compute the optical properties. The asymmetry factor and single-scattering albedo were averaged over the particle size distribution for each of the 28 size distributions (i.e., for each value of $D_{\mathrm{ge}}$ ) as

$$
\begin{aligned}
\bar{g}\left(D_{\mathrm{ge}}\right) & =\frac{\sum_{r} g(r) S_{m}(r)}{\sum_{r} S_{m}(r)} \\
\bar{\omega}\left(D_{\mathrm{ge}}\right) & =\frac{\sum_{r} \omega(r) S_{m}(r)}{\sum_{r} S_{m}(r)} ; \\
S_{m}(r) & =S_{f}(D, L) ; \\
S_{f}^{\text {total }}\left(D_{\mathrm{ge}}\right) & =\sum S_{f}(D, L),
\end{aligned}
$$

where $S_{m}$ and $S_{f}$ are the cross section of crystals from Macke and $\mathrm{Fu}$, respectively. For averaging, their values are set to equal each other in each crystal size bin. The variable $r$ is the surface area equivalent radius. Here, $S_{f}^{\text {total }}$ is the total cross section for a size distribution, and one set of the mean optical properties.

The mean asymmetry factor $(\bar{g})$ and single-scattering albedo $(\bar{\omega})$ are parameterized as functions of $D_{\mathrm{ge}}$ for each crystal shape as

$$
\begin{aligned}
& \bar{g}=X_{1}+X_{2} D_{\mathrm{ge}} \ln \left(D_{\mathrm{ge}}\right)+X_{3} D_{\mathrm{ge}}^{2.5} \ln \left(D_{\mathrm{ge}}\right) \\
& \bar{\omega}=Y_{1}+Y_{2} D_{\mathrm{ge}} \ln \left(D_{\mathrm{ge}}\right)+Y_{3} D_{\mathrm{ge}}^{2.5} \ln \left(D_{\mathrm{ge}}\right)
\end{aligned}
$$


TABLE 2. Values of coefficients of Eqs. (6) and (7) for hexagonal-column-shaped crystals, based on Macke's calculation. Here, $L_{\text {mid }}$ is the middle value of a band.

\begin{tabular}{lcccrrr}
\hline \hline$L_{\text {mid }}(\mu \mathrm{m})$ & $X_{1}$ & $X_{2}$ & $X_{3}$ & $Y_{1}$ & $Y_{3}$ \\
\hline 0.55 & 0.69810 & $-2.3870 \times 10^{-4}$ & $5.2670 \times 10^{-3}$ & 1.00000 & 0.00000 \\
1.04 & 0.70849 & $-1.2059 \times 10^{-4}$ & $3.8725 \times 10^{-3}$ & 0.99993 & $-2.6251 \times 10^{-6}$ & $-1.8423 \times 10^{-5}$ \\
1.25 & 0.72509 & $-4.2147 \times 10^{-5}$ & $2.7750 \times 10^{-3}$ & 0.99985 & $-1.2234 \times 10^{-5}$ & $-7.6890 \times 10^{-5}$ \\
1.43 & 0.74116 & $2.2572 \times 10^{-5}$ & $2.0650 \times 10^{-3}$ & 0.99952 & $-5.3236 \times 10^{-5}$ & $-7.2793 \times 10^{-4}$ \\
1.63 & 0.75776 & $7.3136 \times 10^{-5}$ & $1.5890 \times 10^{-3}$ & 0.99962 & $-5.2751 \times 10^{-5}$ & $-2.1602 \times 10^{-3}$ \\
1.89 & 0.78642 & $1.2665 \times 10^{-4}$ & $4.4843 \times 10^{-4}$ & 0.99958 & $-6.0179 \times 10^{-5}$ & $-1.7144 \times 10^{-3}$ \\
2.15 & 0.80205 & $1.8245 \times 10^{-4}$ & $-2.9726 \times 10^{-4}$ & 0.99957 & $-5.3724 \times 10^{-5}$ & $-2.2280 \times 10^{-3}$ \\
2.59 & 0.86983 & $2.5360 \times 10^{-4}$ & $-1.8575 \times 10^{-3}$ & 0.99823 & $-2.3566 \times 10^{-5}$ & $-3.6486 \times 10^{-3}$ \\
3.28 & 0.93400 & $4.3244 \times 10^{-4}$ & $-5.6146 \times 10^{-3}$ & 0.55938 & $1.0971 \times 10^{-5}$ & $-8.9058 \times 10^{-5}$ \\
\hline
\end{tabular}

where $X_{i}$ and $Y_{i}(i=1,2,3)$ are wavelength-dependent coefficients that are given in Tables 2,3 , and 4 for hexagonal column, hexagonal plate and polycrystals shaped crystals, respectively.

Figures $1 \mathrm{a}$ and $1 \mathrm{~b}$ show the mean asymmetry factors and single scattering albedos as a function of $D_{\mathrm{ge}}$ at four wavelengths. For comparison, results derived from Fu's parameterization for hexagonal columns (Fu 1996) are also shown. In general, Macke's values of $g(\omega)$ for hexagonal columns are smaller (larger) than Fu's, which may be caused by uncertainties in both parameterizations, due to a small number of samples or by different treatments of the ice crystal aspect ratio. Fu (1996) used the aspect ratio (D/L) based on Auer and Veal (1970):

$$
D / L= \begin{cases}1.0 & 0<L \leq 30 \mu \mathrm{m} \\ 0.8 & 30<L \leq 80 \mu \mathrm{m} \\ 0.5 & 80<L \leq 200 \mu \mathrm{m} \\ 0.34 & 200<L \leq 500 \mu \mathrm{m} \\ 0.22 & L>500 \mu \mathrm{m},\end{cases}
$$

and Macke et al. (1996) used the aspect ratio suggested by Heymsfield (1977):

$$
D= \begin{cases}0.142 L^{0.7556} & \text { when } L \leq 30 \mu \mathrm{m} \\ 0.064 L^{0.53} & \text { when } L>30 \mu \mathrm{m} .\end{cases}
$$

The column-shaped crystals are more compact using the latter aspect ratio function. Measurements indicate that the aspect ratio in real clouds vary considerably so that any single value cannot represent all cirrus clouds adequately (Heymsfield et al. 1998). Fu (1996) used a more physically based treatment of small ice crystals with the extinction coefficient changing slightly with wavelength, whereas Macke et al. (1996) assumed the extinction coefficient as a constant for ice crystals. The extinction cross section for a single ice crystal by Macke is assumed to be $2 A$ where $A$ is the cross section of the ice crystal. Therefore, the extinction coefficient $\beta$, described by

$$
\beta=\operatorname{IWC}\left(1.8135 \times 10^{-5}+2.51806 / D_{\text {ge }}\right),
$$

is valid for all wavelengths.

\section{Sensitivity tests}

The basic approach of retrieving the SSRB follows the method proposed by Li et al. (1993), which relates the SSRB to TOA-reflected flux by the following linear relationship:

$$
R_{\mathrm{abs}}=\alpha_{0}\left(\mu_{0}, p\right)-\beta_{0}\left(\mu_{0}, p\right) R_{\mathrm{ref}},
$$

where $R_{\text {abs }}$ and $R_{\text {ref }}$ denote the SSRB and TOA-reflected fluxes normalized by irradiance incident upon the TOA, respectively. Therefore, $R_{\text {ref }}$ is the local planetary albedo, $\mu_{0}$ is the cosine of SZA (the solar zenith angle), and $p$ is the precipitable water (total column water vapor) in the atmospheric column. The intercept and slope were parameterized for clear sky and four types of clouds including a single ice cloud with fixed optical properties. In this study, the clear-sky model is treated as the baseline model for it has been validated and used widely in previous studies ( $\mathrm{Li}$ et al. 1993; Ramanathan et al. 1995; Waliser et al. 1996; Conant et al. 1997; Li

TABLE 3. Values of coefficients of Eqs. (6) and (7) for hexagonal-plate-shaped crystals, based on Macke's calculation. Here, $L_{\text {mid }}$ is the middle value of a band.

\begin{tabular}{lccccrr}
\hline \hline$L_{\text {mid }}(\mu \mathrm{m})$ & $X_{1}$ & $X_{2}$ & $X_{3}$ & $Y_{1}$ & $Y_{3}$ \\
\hline 0.55 & 0.72305 & $-3.3100 \times 10^{-4}$ & $7.1999 \times 10^{-3}$ & 1.00000 & 0.00000 \\
1.04 & 0.73165 & $-2.1825 \times 10^{-4}$ & $5.8303 \times 10^{-3}$ & 0.99996 & $-3.4117 \times 10^{-7}$ & $-2.0692 \times 10^{-5}$ \\
1.25 & 0.74580 & $-1.4712 \times 10^{-4}$ & $4.8005 \times 10^{-3}$ & 0.99964 & $-2.1820 \times 10^{-6}$ & $-7.9374 \times 10^{-5}$ \\
1.43 & 0.75992 & $-1.0040 \times 10^{-4}$ & $4.1637 \times 10^{-3}$ & 0.99734 & $-1.7640 \times 10^{-6}$ & $-6.1049 \times 10^{-4}$ \\
1.63 & 0.77564 & $-6.2539 \times 10^{-5}$ & $3.5748 \times 10^{-3}$ & 0.99302 & $-2.3729 \times 10^{-5}$ & $-1.5700 \times 10^{-3}$ \\
1.89 & 0.79599 & $2.50013 \times 10^{-5}$ & $2.4472 \times 10^{-3}$ & 0.99451 & $1.4742 \times 10^{-5}$ & $-1.3062 \times 10^{-3}$ \\
2.15 & 0.81303 & $3.5911 \times 10^{-5}$ & $1.8152 \times 10^{-3}$ & 0.99275 & $2.4728 \times 10^{-5}$ & $-1.6316 \times 10^{-3}$ \\
2.59 & 0.86728 & $1.1735 \times 10^{-4}$ & $1.1182 \times 10^{-4}$ & 0.98762 & $5.6058 \times 10^{-5}$ & $-2.5860 \times 10^{-3}$ \\
3.28 & 0.92535 & $4.0465 \times 10^{-4}$ & $-4.9762 \times 10^{-3}$ & 0.56244 & $9.0163 \times 10^{-6}$ & $-4.5407 \times 10^{-5}$ \\
\hline
\end{tabular}


TABLE 4. Values of coefficients of Eqs. (6) and (7) for polycrystal-shaped crystals, based on Macke's calculation. Here, $L_{\text {mid }}$ is the middle value of a band.

\begin{tabular}{lcrrrrr}
\hline \hline & $L_{\text {mid }}(\mu \mathrm{m})$ & $X_{1}$ & $X_{2}$ & $X_{3}$ & $Y_{1}$ & $Y_{3}$ \\
\hline 0.55 & 0.67020 & $-2.7501 \times 10^{-5}$ & $1.5873 \times 10^{-3}$ & 1.00000 & 0.00000 \\
1.04 & 0.69015 & $-3.7351 \times 10^{-5}$ & $1.4799 \times 10^{-3}$ & 0.99973 & $-5.7481 \times 10^{-6}$ & $2.1252 \times 10^{-5}$ \\
1.25 & 0.70707 & $1.3142 \times 10^{-4}$ & $-6.1788 \times 10^{-4}$ & 0.99926 & $-2.0954 \times 10^{-5}$ & $4.1366 \times 10^{-5}$ \\
1.43 & 0.70525 & $9.5645 \times 10^{-5}$ & $-4.3349 \times 10^{-5}$ & 0.99609 & $-1.1611 \times 10^{-4}$ & $7.0333 \times 10^{-5}$ \\
1.63 & 0.73079 & $3.1609 \times 10^{-4}$ & $-2.0079 \times 10^{-3}$ & 0.99204 & $-2.1623 \times 10^{-4}$ & $-2.4780 \times 10^{-4}$ \\
1.89 & 0.74935 & $3.1180 \times 10^{-4}$ & $-2.5470 \times 10^{-3}$ & 0.99326 & $-1.9255 \times 10^{-4}$ & $-1.4265 \times 10^{-4}$ \\
2.15 & 0.77278 & $3.4927 \times 10^{-4}$ & $-3.1013 \times 10^{-4}$ & 0.99266 & $-2.0853 \times 10^{-4}$ & $-3.8363 \times 10^{-4}$ \\
2.59 & 0.80314 & $2.2063 \times 10^{-4}$ & $-1.1750 \times 10^{-3}$ & 0.99093 & $-2.1836 \times 10^{-4}$ & $-1.2499 \times 10^{-3}$ \\
3.28 & 0.78531 & $1.3337 \times 10^{-4}$ & $2.8656 \times 10^{-4}$ & 0.59291 & $8.6667 \times 10^{-5}$ & $-1.9992 \times 10^{-3}$ \\
\hline
\end{tabular}

1998). Nevertheless, the parameterization has certain inherent limitations. A lack of explicit accounting for the effect of absorbing aerosol (note the algorithm is not affected by scattering aerosol) may cause significant errors for an aerosol-laden atmosphere such as fire active regions in the Tropics ( $\mathrm{Li} \mathrm{1998)}$ and under ice cloud conditions. A correction was introduced by Masuda et al. (1995) to account for the effect of aerosol, together with other corrections for water clouds including cloudtop height and droplet size. This study basically attempts to improve the performance under ice cloud conditions that have not been addressed.

Note that the study of Li et al. (1993) was based on a doubling-adding code coupled with the Low Resolution Atmospheric Radiance and Transmission Model version 6 (LOWTRAN-6), while the current investigation employs the $\mathrm{Fu}$-Liou $\delta$-four-stream radiative transfer model with MODTRAN-3.5. To check if there is any systematic drift due to the change in models, the results of clear-sky simulations computed by the current model are substituted into the clear-sky parameterization scheme of Li et al. (1993). The differences in the SSRB estimated by the $\mathrm{Li}$ et al. parameterization and computed by the Fu-Liou model vary with surface type but are generally rather small, between -6 and $+4 \mathrm{~W} \mathrm{~m}^{-2}$ for land and snow/ice surface types, and within $10 \mathrm{~W} \mathrm{~m}^{-2}$ for the ocean water surface, for SZA of $60^{\circ}$. This suggests that the original clear-sky algorithm can be considered as the baseline for this study.

\section{a. Ice crystal shape}

Based on the optical properties of different shapes of ice crystals (cf. Fig. 1), the SSRB and TOA upward solar radiative flux $\left(F_{\text {ref }}\right)$ were computed and are shown in Fig. 2. Both variables are very sensitive to ice crystal shape (Fig. 2a). For fixed amounts of IWC, the lowest SSRB and highest $F_{\text {ref }}$ correspond to ice clouds comprised of polycrystals shape; the reverse is true for ice clouds composed of plate crystals. Maximum differences in the SSRB and $F_{\text {ref }}$ among the three crystal shapes amount to $50-70 \mathrm{~W} \mathrm{~m}^{-2}$. Furthermore, for cloud particles of columnar shape, the values of the SSRB derived using Macke's method is higher than that using Fu's method. This discrepancy is attributed to differ- ences in the optical properties originating from different treatments of light scattering. Although both the SSRB and $R_{\text {ref }}$ are very sensitive to ice crystal shape, the sensitivity of the linear relationship between them is lessened dramatically, as shown in Fig. 2b, since the crystal shape has similar but opposite influences on the two individual fluxes. The data points for all crystal shapes obtained by Macke's method are distributed tightly along a line with a small degree of scattering, indicating a weak effect of the crystal shape on the relationship. As a result, differences in the SSRB retrieved using a single regression model derived for one crystal shape but applied to other cloud shapes are small but still significant, as shown in Fig. 2c. The differences are determined from the retrievals of the SSRB for three ice crystal shapes (columns, plates, and polycrystals by Macke, and hexagonal columns by $\mathrm{Fu}$ ) using a regression model developed for columnar crystals by Macke. The results indicate that the SSRB retrieved from $F_{\text {ref }}$ is not overly sensitive to ice crystal shape. In fact, discrepancies induced by the use of different nonspherical estimation methods (Macke's vs Fu-Liou's) are even larger than those resulting from different ice crystal shapes. Since ice crystal shape is very difficult to retrieve by means of remote sensing, SSRB retrievals without knowledge of crystal shape may not lead to significant errors.

\section{b. Cloud particle size and cloud-top height}

Figure 3 illustrates the sensitivities of the intercept and the slope of the relationship between SSRB $\left(F_{\text {abs }}\right)$ and $F_{\text {ref }}$ to ice crystal effective size $D_{\text {ge }}$. The results were obtained for ice clouds consisting of columnar crystals using Fu's method. The calculations were done for eight IWC values varying from 0.01 to $0.08 \mathrm{~g} \mathrm{~m}^{-3}$; cloudtop height was fixed at $11 \mathrm{~km}$, cloud base at $6 \mathrm{~km}$; and 16 values of SZA were assigned between $1^{\circ}$ and $76^{\circ}$ over various types of land (type 1-15) and ocean (type 17). The middle latitude summer (MLS) atmosphere was assumed. Each pair of cloud-sky intercept and slope values in the figure was fitted by regression of the results obtained for 128 cases with varying IWC and surface types. For comparison, the values for clear sky are also plotted that were fitted with 16 surface types. In the 
(a)
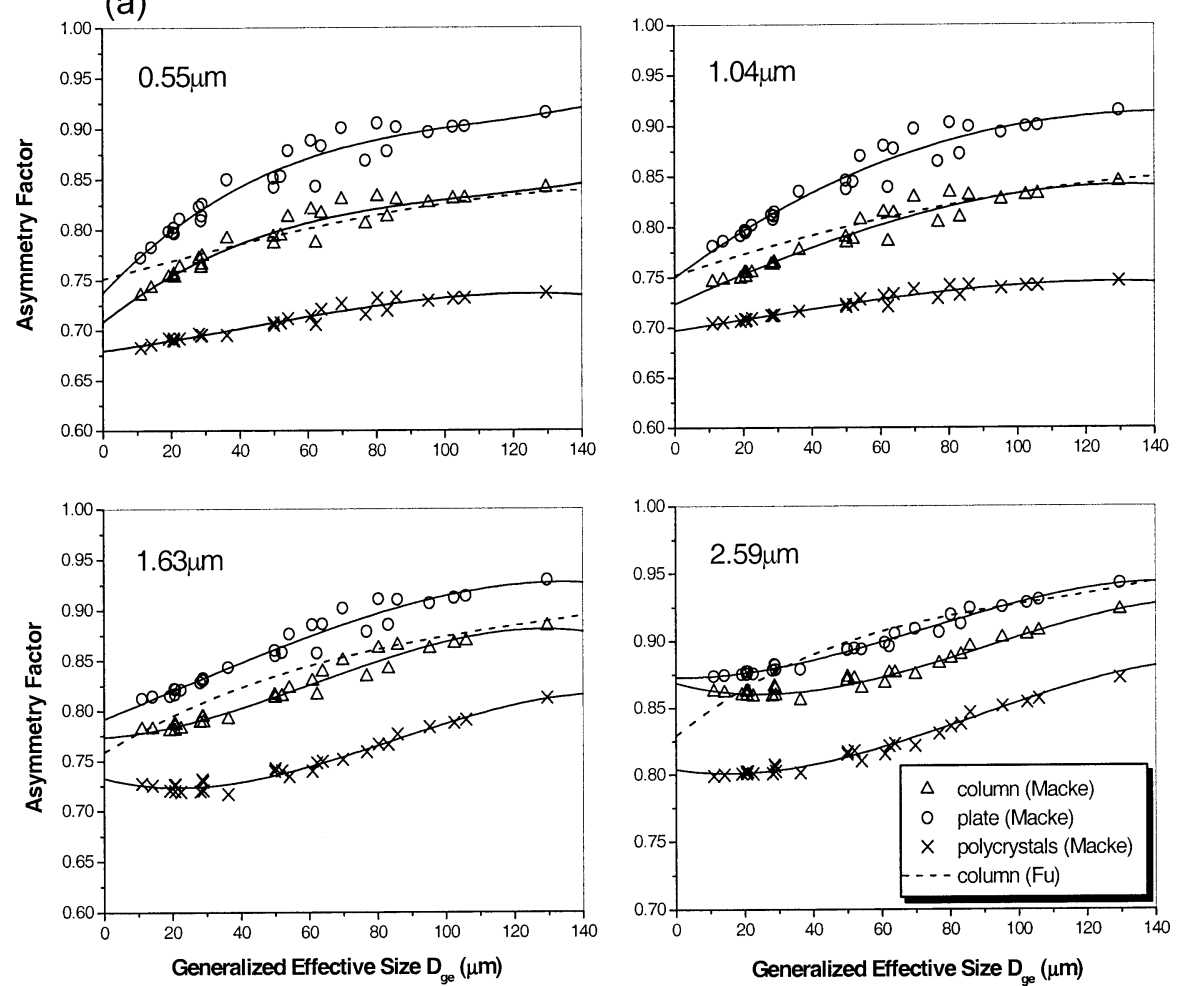

(b)
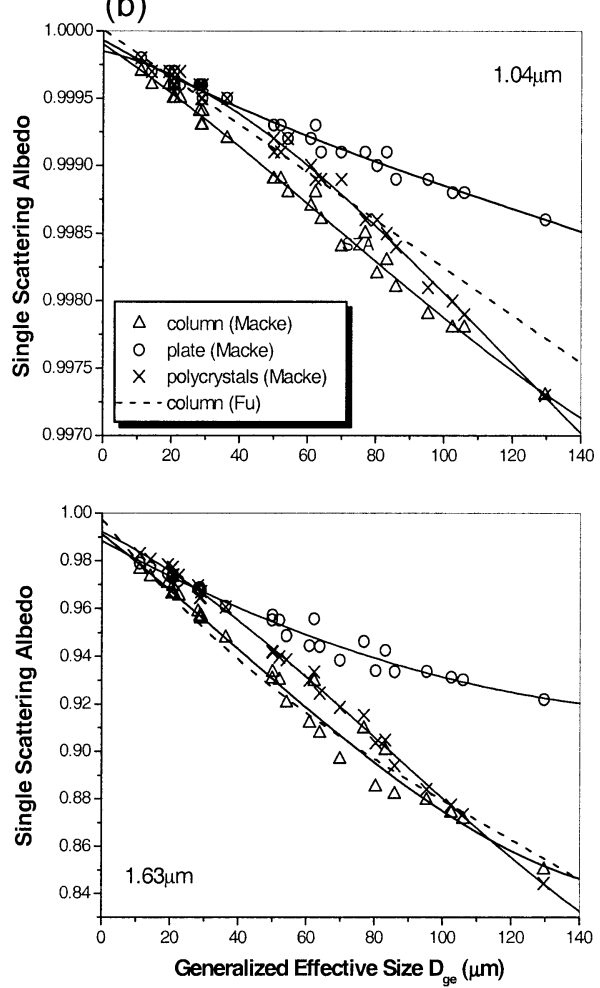
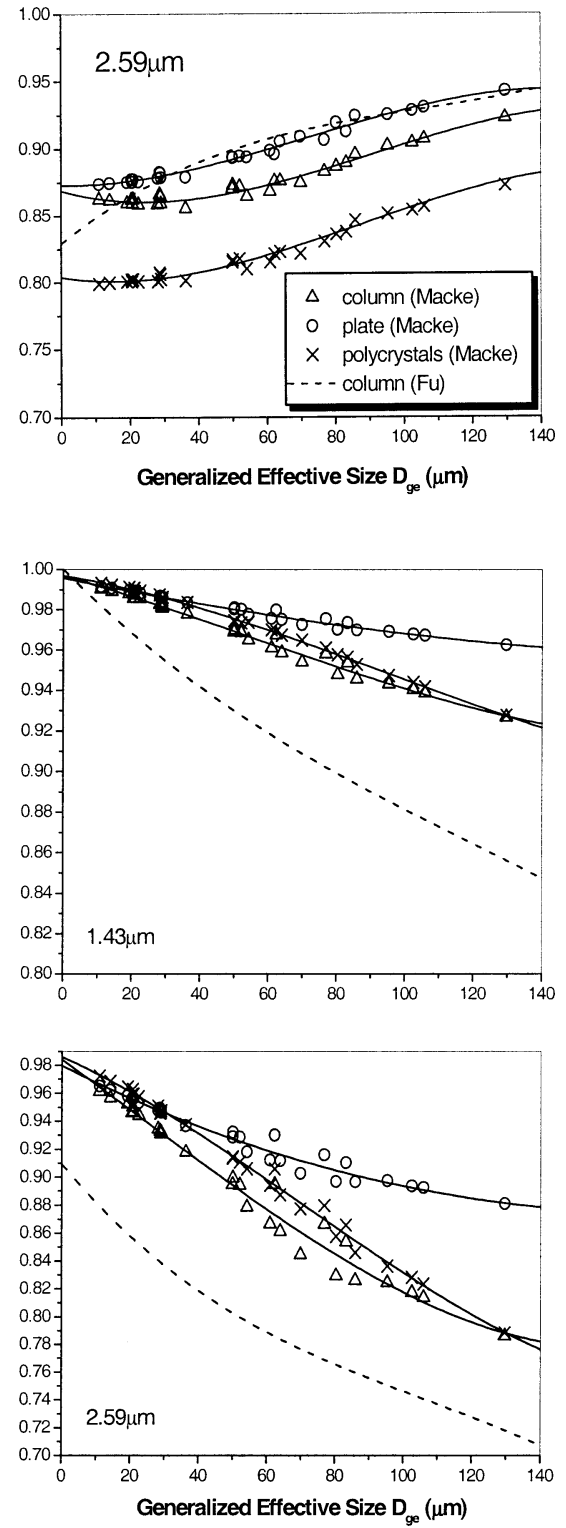

FIG. 1. (a) The mean asymmetry factor and (b) single-scattering albedo as a function of generalized effective size $\left(D_{\mathrm{ge}}\right)$ at four wavelengths. 

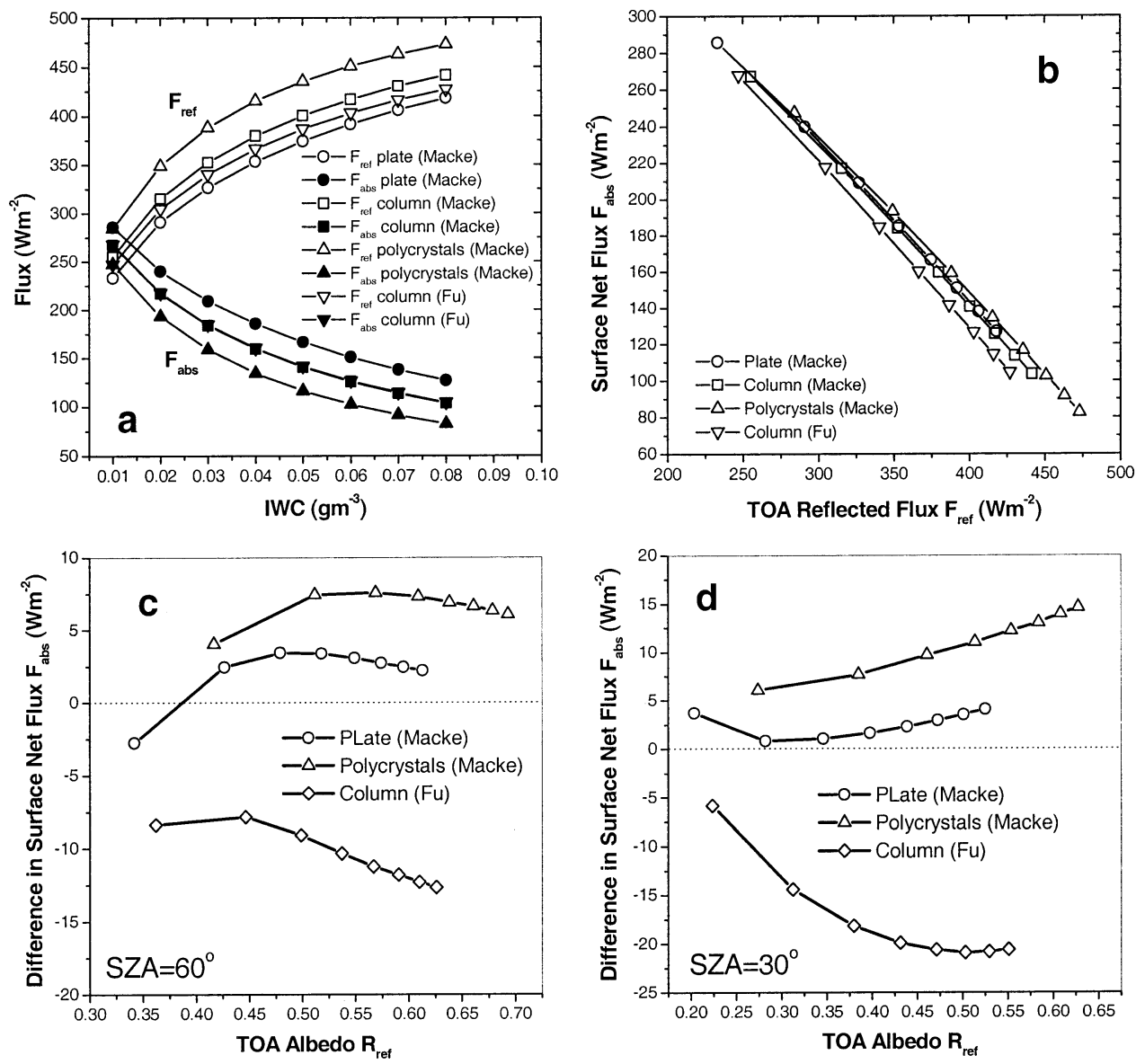

FIG. 2. (a) The sensitivities of SSRB $\left(F_{\text {abs }}\right)$ and TOA-reflected solar radiative flux $\left(F_{\text {ref }}\right)$ to ice crystal shape for SZA of $60^{\circ}$. (b) The sensitivity of the linear relationship between $F_{\text {abs }}$ and $F_{\text {ref }}$ to ice crystal shape for SZA of $60^{\circ}$. (c) Differences in SSRB retrieved from $F_{\text {ref }}$ (or $R_{\text {ref }}$ ) between column crystals by Macke and other crystal shapes for SZA of $60^{\circ}$. (d) Same as (c) but for SZA of $30^{\circ}$. Here, $D_{\mathrm{ge}}$ is $50 \mu \mathrm{m}$ and the cloud is located between 11 and $9 \mathrm{~km}$.

majority of cases, the magnitude of the slope in the cloudy sky (ice cloud) is less than that of clear sky. Also, the slope is more sensitive to cloud particle size than is the intercept. Except for very large SZA, the magnitude of slope increases dramatically with increasing $D_{\mathrm{ge}}$. The dependence may be explained as follows. Note that the absolute value of the slope determines how the addition of a cloud layer affects the absorption of solar energy in the entire atmospheric column, relative to clear-sky absorption ( $\mathrm{Li}$ 1998). If its value is larger than unity, the cloud enhances atmospheric absorption and the larger the slope, the greater the enhancement in atmospheric absorption. Otherwise, atmospheric absorption is diminished. As seen in Fig. 1, large crystal particles have smaller single-scattering albedos and thus stronger cloud absorption, leading to a larger value of the slope. Since almost all the cases presented here have slopes less than unity, ice cloud particles generally decrease atmospheric absorption, relative to clear-sky atmospheric absorption due to water droplets, aerosols, and water vapor. The driving factor for this is the location of ice clouds (Chou et al. 1995). They are generally located so high in the atmosphere that the absorption path above them is short and reflection is dominant. As a result, photons are more likely to be reflected by ice crystals before they have any chance being absorbed by the absorbing agents below. Also, the magnitude of the slope has a strong dependence on SZA. The larger SZA, the smaller the slope. This is attributed to an increased path length at a larger SZA that reflects more solar radiation than at a smaller SZA.

Errors in the SSRB $\left(F_{\text {abs }}\right)$ retrieval due to insufficient knowledge of cloud particle effective size and cloudtop height are further demonstrated in Fig. 4. It shows the differences in the SSRB retrieved under various ice cloud conditions with respect to a reference cloud case with the same SZA. The reference case chosen is an ice cloud with an effective particle size of $60 \mu \mathrm{m}$, located between 6 and $11 \mathrm{~km}$ over all types of surfaces $(1 \sim$ 17 types in Table 1). The retrieval is done by first fitting a linear regression equation [Eq. (11)] for the reference 

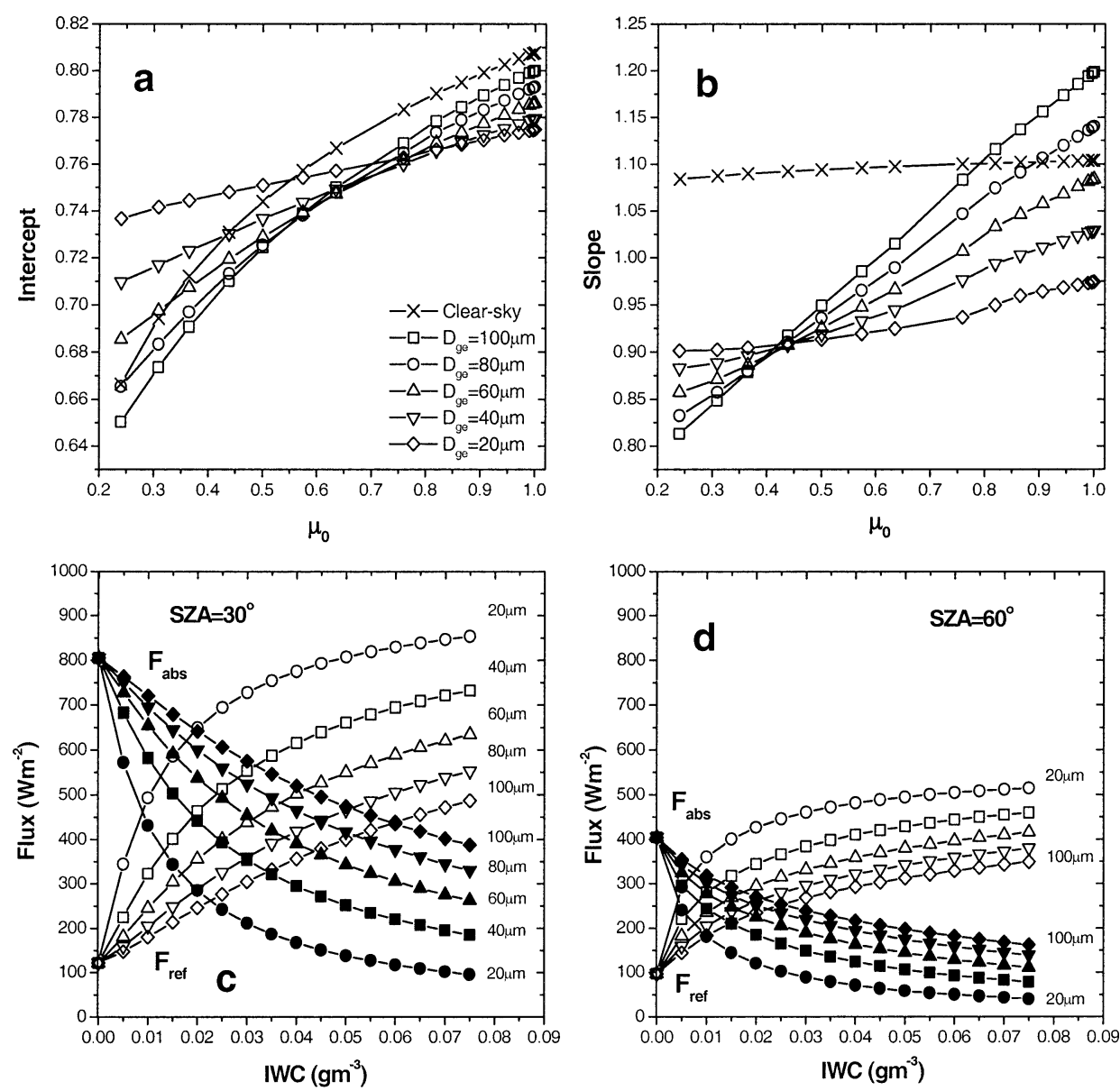

FIG. 3. The sensitivities of the (a) intercept and (b) slope of the relationship between SSRB $\left(F_{\text {abs }}\right)$ and the reflected flux at TOA $\left(F_{\text {ref }}\right)$ to ice crystal effective size $D_{\text {ge }}$ for 16 values of SZA between $1^{\circ}$ and $76^{\circ}$ over different land types (types 1-15) and ocean surface (type 17). The cloud is located between 6 and $11 \mathrm{~km}$. The MLS atmosphere was assumed. The sensitivities of $F_{\text {abs }}$ and $F_{\text {ref }}$ to $D_{\mathrm{ge}}$ for a value of SZA of (c) $30^{\circ}$ and (d) $60^{\circ}$, respectively.

case with fixed SZA, cloud particle size, and height, but varying IWC and surface type. The regression turned out to be $R_{\text {abs }}=0.798-1.027 R_{\text {ref }}$ for $\mathrm{SZA}=30^{\circ}$, and $R_{\text {abs }}=0.742-0.904 R_{\text {ref }}$ for $\mathrm{SZA}=60^{\circ}$. For reflected TOA fluxes computed for different cloud cases, a set of SSRB values is estimated using the regression equations. The retrieved SSRB is then subtracted from that computed by the detailed radiative transfer model. Figures $4 \mathrm{a}$ and $4 \mathrm{~b}$ show the differences in SSRB against cloud optical depth for cloud particle size $\left(D_{\mathrm{ge}}\right)$ varying from 10 to $130 \mu \mathrm{m}$ but fixed cloud top $(11 \mathrm{~km})$ and bottom $(6 \mathrm{~km})$. Figures $4 \mathrm{c}$ and $4 \mathrm{~d}$ are for fixed $D_{\mathrm{ge}}$ of $60 \mu \mathrm{m}$ but varying cloud top $(7 \sim 13 \mathrm{~km})$.

Relative to ice crystal size, the effect of cloud top on the relationship between $F_{\text {abs }}$ and $F_{\text {ref }}$ is much less sensitive. For example, for SZA $=30^{\circ}$ and cloud optical depth below 10, errors due to misinterpretation of cloud top are from +30 to $-25 \mathrm{~W} \mathrm{~m}^{-2}$. However, errors due to misinterpretation of $D_{\mathrm{ge}}$ are from +35 to $-50 \mathrm{~W}$ $\mathrm{m}^{-2}$. As ice clouds are usually high in the atmosphere, a shift in cloud-top height within a reasonable range does not significantly affect the total atmospheric absorption. This is because radiation reflected by ice clouds misses the most important atmospheric absorption agents such as aerosols and water vapor situated at the lower troposphere. If the cloud top were within the atmospheric boundary layer, which hosts the bulk of the atmosphere's water vapor and aerosol, its effects would be much more significant. Therefore, it is more important to take into account ice crystal effective size than ice-cloud-top height in order to improve the retrieval of the SSRB from TOA-reflected flux.

\section{c. Vertical profile of crystal size}

Due to gravitational sedimentation of crystals in ice clouds, the mean size of ice crystals generally decreases with height. The rate of change depends on the age, location and microphysics of a cloud. From the cirrus measurements during the First ISCCP Regional Exper- 

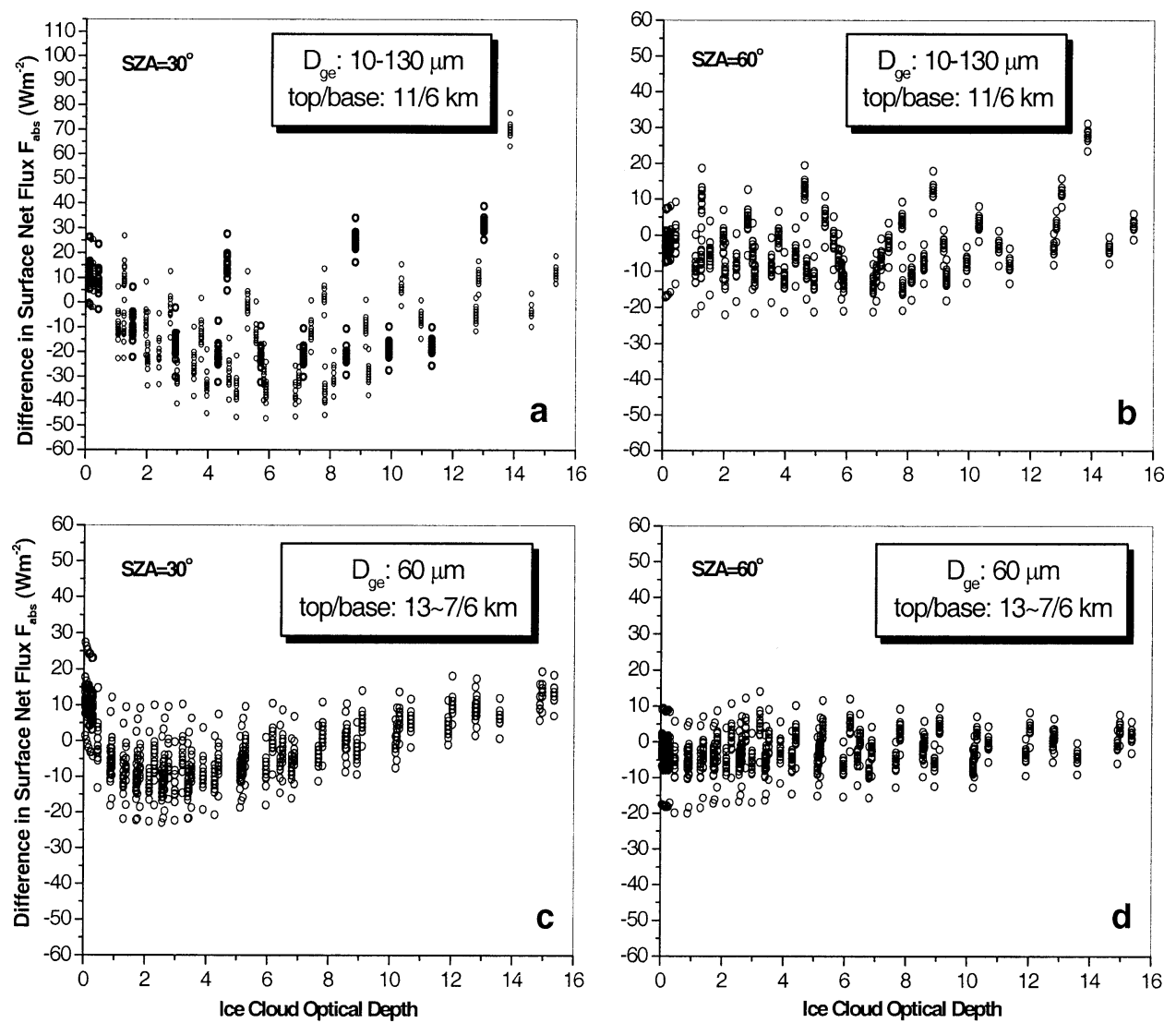

FIG. 4. The errors in the SSRB retrieval plotted against ice cloud optical depth for two SZA values $\left(30^{\circ}\right.$ and $60^{\circ}$ ) due to differences in (a), (b) cloud particle effective size $D_{\text {ge }}$ (changing from 10 to $130 \mu \mathrm{m}$ ) and (c), (d) cloud-top height (from 7 to $13 \mathrm{~km}$ ) between various cloud cases and a reference cloud case. The reference case is an ice cloud located between 6 and $11 \mathrm{~km}$, with $D_{\mathrm{ge}}$ of $60 \mu \mathrm{m}$, over the 17 types of surface shown in Table 1.

iment (FIRE) II, Heymsfield et al. (1998) reported that mean crystal sizes were tens of microns at the cloud top, $150-200 \mu \mathrm{m}$ in the midcloud region, and maximum of about $600 \mu \mathrm{m}$ near the cloud bottom. Such a strong variation in the vertical structure of cirrus clouds may have very different effects on the SSRB and TOA-upward flux from that of water clouds. Small crystals at the cloud top, even though they are in a thin layer, reflect more solar energy (and thus less arrives at the surface) than a cloud with a vertically constant mean crystal size. To study the sensitivity of the SSRB to the vertical profile of ice crystal size, five idealized cases were chosen, and are shown in Fig. 5a. These cases have different vertical profiles of $D_{\mathrm{ge}}$, but the same vertically averaged $D_{\text {ge }}$ of $60 \mu \mathrm{m}$. The vertical profile is specified by the decreasing rate $\Delta D$ defined as a decrease in $D_{\text {ge }}$ per kilometer. Figure $5 \mathrm{~b}$ shows the impact of crystal size vertical profile on the SSRB and the reflected solar radiative flux at the TOA. The smaller the cloud particles at the cloud top, the higher the TOA-upward flux, and thus the lower the SSRB. The value of $D_{\mathrm{ge}}$ at the lower part of clouds has a smaller impact on both fluxes, explaining the larger gaps between reflected fluxes than between the SSRB. The linear relationships between the two fluxes are shown in Fig. 5c. The discrepancies among the regression lines indicate that the vertical inhomogeneity in crystal size profile does affect the relationship, which is mainly exerted by a disparity in ice crystal size near the cloud top. If $D_{\mathrm{ge}}$ is fixed at the cloud top but varies downward (see the cases with $\Delta D$ $=20 \mu \mathrm{m}$ and nonlinear case 2), the impact of crystal size variation diminishes considerably. Figure $5 \mathrm{~d}$ shows errors in the SSRB retrievals for $\Delta D=10,20 \mu \mathrm{m}$, and a nonlinear case (case 1) using a regression equation derived for $\Delta D=0$. The errors are largest (25-30 W $\mathrm{m}^{-2}$ ) for the nonlinear case, moderate $\left(10-20 \mathrm{~W} \mathrm{~m}^{-2}\right)$ for $\Delta D=20 \mu \mathrm{m}$, and smallest $\left(\sim 5 \mathrm{~W} \mathrm{~m}^{-2}\right)$ for $\Delta D=$ $10 \mu \mathrm{m}$. These magnitudes of errors are basically proportional to the differences in $D_{\mathrm{ge}}$ at the cloud top. Therefore, to the first order of approximation, one may rely on cloud particle size information at the cloud top to approximately account for this effect. From the viewpoint of passive spaceborne remote sensing, it is always easier to derive cloud parameters at the top than the interior, while active remote sensing (lidar or radar) is able to penetrate through the cloud. Of course, in situ 

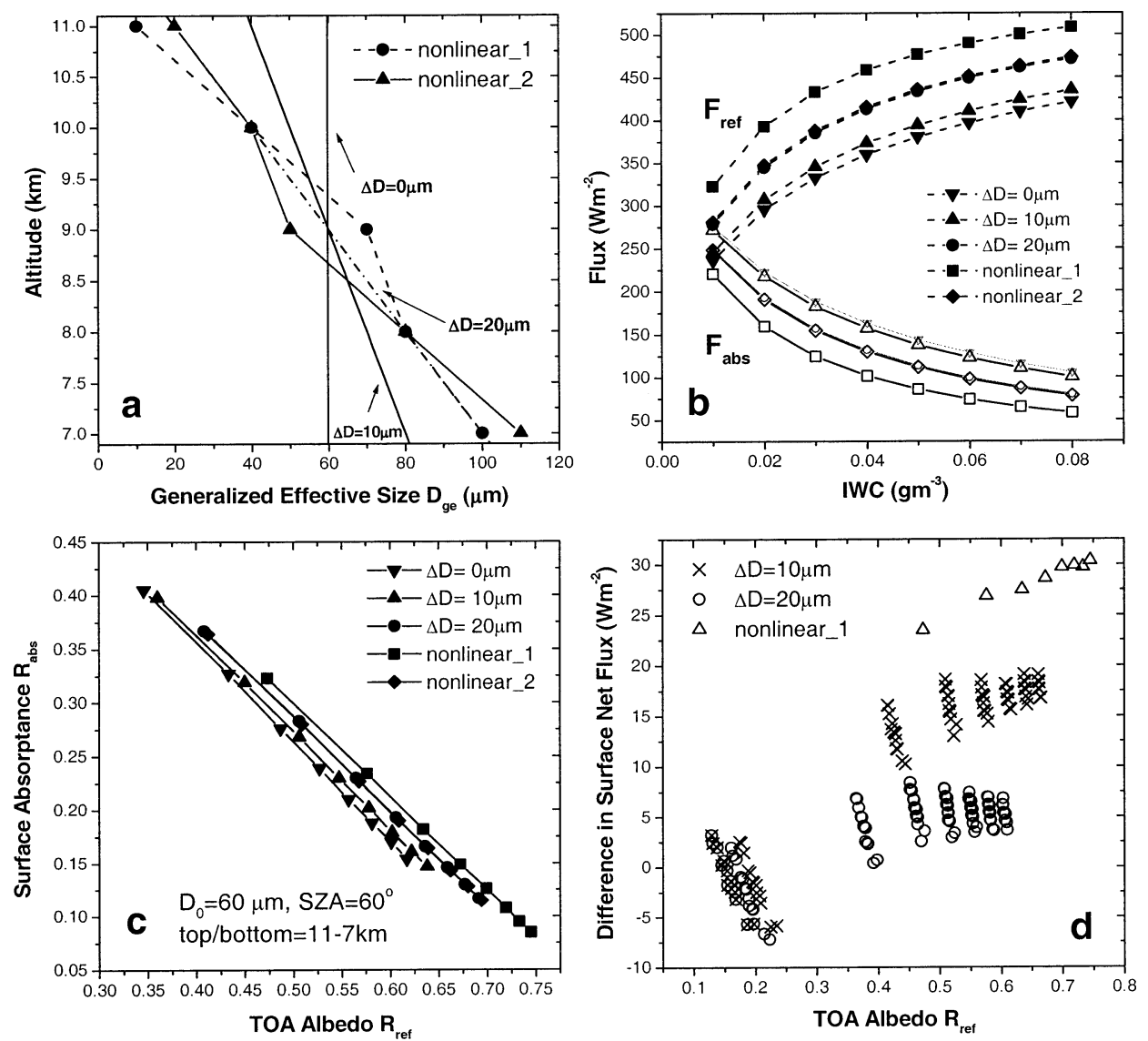

FIG. 5. (a) Five idealized cases with different vertical profiles of $D_{\text {ge }}$, but the same vertically averaged $D_{\mathrm{ge}}$ of $60 \mu \mathrm{m}$. Here, $\Delta D$ is the decrease in $D_{\mathrm{ge}}$ per kilometer. (b) SSRB $\left(F_{\text {abs }}\right)$ and the reflected solar radiative flux at TOA $\left(F_{\text {ref }}\right)$ for the five cases shown in (a). (c) The relationships between SSRB and the reflected solar radiative flux at TOA for the five cases in (a). (d) The errors in the SSRB retrievals for $\Delta D=10$, $20 \mu \mathrm{m}$ and a nonlinear case (case 1) due to using a regression equation derived for $\Delta D=0$. For all cases, the cloud top/base were fixed at 11 and $7 \mathrm{~km}$, respectively.

cloud measurements can provide the most reliable information on the vertical structure.

\section{d. Multiphase multilayer clouds}

Ice clouds are often situated above water clouds. For investigating the impact of overlapping cloud on solar fluxes, multiphase multilayer clouds with various IWCs (or optical depth) are considered. The upper-layer ice clouds located between 9 and $11 \mathrm{~km}$ (or 6 and $8 \mathrm{~km}$ ) have the same microphysical properties $\left(D_{\mathrm{ge}}=60 \mu \mathrm{m}\right)$. The lower-layer water clouds have effective size $r_{e}$ of $10 \mu \mathrm{m}$ located between $1-2 \mathrm{~km}$. For the sake of comparison, two monophase single-layer clouds, water $\left(r_{e}\right.$ $=10 \mu \mathrm{m})$, and ice $\left(D_{\mathrm{ge}}=60 \mu \mathrm{m}\right)$ clouds are also considered. Figure 6a presents the relationships between $F_{\text {abs }}$ and $F_{\text {ref }}$ for these multi- and monophase clouds over two surfaces (mixed forest and ocean water) with a SZA of $60^{\circ}$. For a given value of $F_{\text {ref }}$, values of $F_{\text {abs }}$ for all multiphase multilayer clouds are smaller than those in the single-layered ice cloud skies, but larger than in the single-layered water cloud skies. In the multiphase multilayered cases, the solar radiation absorbed in the clouds and the atmosphere is larger than in single-layered ice cloud sky cases. Therefore, the solar radiation absorbed at the ground is reduced. Figure $6 \mathrm{~b}$ shows the variations in the SSRB and TOA-reflected fluxes with cloud optical depth for cases of two individual single-layered clouds (an ice cloud with $D_{\mathrm{ge}}$ of $60 \mu \mathrm{m}$ between 9 and $11 \mathrm{~km}$, and a water cloud with $r_{e}$ of $10 \mu \mathrm{m}$ between 1 and 2 $\mathrm{km})$ and their combinations. The flux at the TOA has very large differences between single-layered ice clouds and other clouds, while SSRB values are relatively close. It is thus apt to get big errors in the retrieval of SSRB from reflected fluxes at the TOA, if a multilayer multiphase cloud is regarded as a single-layer ice cloud sky. Figure $6 \mathrm{c}$ shows such errors as a function of total cloud optical depth. The error varies within $\sim 35 \mathrm{~W} \mathrm{~m}^{-2}$ for SZA $=60^{\circ}$ depending on the optical depth of ice and water clouds (for optical depth of water cloud below 10 ), and the error is insensitive to the surface type. The error is large for a thin ice cloud situated above a thick 

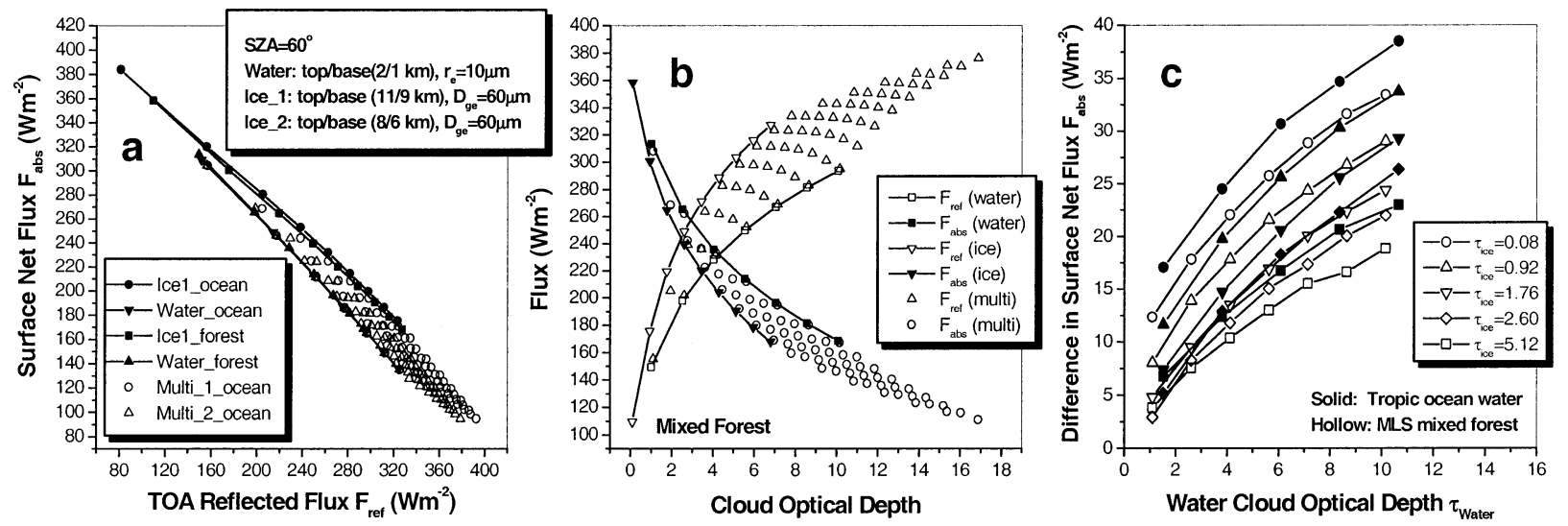

FIG. 6. (a) The relationships between surface net flux $F_{\text {abs }}$ and TOA-reflected flux $F_{\text {ref }}$ for multi- and monophase clouds over two types of surfaces (mixed forest and ocean water), with a SZA of $60^{\circ}$. The cloud cases include single-layer clouds, an ice cloud with $D_{\text {ge }}$ of $60 \mu \mathrm{m}$ between 9 and $11 \mathrm{~km}$ (Multi_1) or 6 and $8 \mathrm{~km}$ (Multi_2), and a water cloud with $r_{e}$ of $10 \mu \mathrm{m}$ between 1 and $2 \mathrm{~km}$, as well as their combinations. (b) The dependence of $F_{\text {abs }}$ and $F_{\text {ref }}$ on cloud optical depth. (c) Errors in the $\left(F_{\text {abs }}\right)$ retrieval of SSRB as a function of water/ ice cloud optical depth by treating a multilayer multiphase cloud as a single-layer ice cloud for two surfaces (mixed forest and ocean water).

water cloud. However, the errors incurred by treating a multilayered multiphase cloud as a single-layered ice cloud are less than those resulting from treating the ice layer as water clouds. They are dictated by the differences between ice and water clouds in their particle sizes, optical thickness, and cloud-top height, among other factors.

\section{Revised parameterization for ice cloud sky}

Parameterization of the relationship between $R_{\mathrm{abs}}$ and $R_{\text {ref }}$ for an ice cloud sky is based on the clear-sky baseline model of Li et al. (1993). According to the results of sensitivity tests, corrections for an ice cloud sky are needed to account for two most influential parameters, namely, the crystal effective size $D_{\mathrm{ge}}$ (primarily in the top layer) and cloud-top height $Z_{t}$, as well as $\mu$ and the

TABle 5. Parameterized terms of the intercept and slope used in Eqs. (12) and (13).

\begin{tabular}{|c|c|}
\hline Terms & Parameterization \\
\hline$\Delta \alpha_{d}$ & $\begin{array}{l}0.02212-0.17939 \ln \left(\mu_{0}\right)-0.0437 \ln \left(D_{\mathrm{ge}}\right) \\
\quad+0.01944\left[\ln \left(\mu_{0}\right)\right]^{2}+0.0082\left[\ln \left(D_{\mathrm{ge}}\right)\right]^{2} \\
\quad+0.04609 \ln \left(\mu_{0}\right) \ln \left(D_{\mathrm{ge}}\right)\end{array}$ \\
\hline$\Delta \beta_{d}$ & $\begin{array}{l}-0.16862-0.05361 \mu_{0}-0.00218 D_{\mathrm{ge}}+0.04011 \mu_{0}^{2} \\
\quad+1.88541 \times 10^{-6} D_{\mathrm{ge}}^{2}+0.0048 \mu_{0} D_{\mathrm{ge}}\end{array}$ \\
\hline$\Delta \alpha_{z}$ & $\begin{array}{l}{\left[0.00182+3.7045 \times 10^{-4} \mu_{0}-2.6323 \times 10^{-4} \mu_{0}^{2}\right.} \\
\left.-8.1743 \times 10^{-4} \ln \left(Z_{t}\right)\right] \\
\quad \div \quad\left\{1.0-0.01803 \mu_{0}-0.93955 \ln \left(Z_{t}\right)\right. \\
\left.\quad+0.20939\left[\ln \left(Z_{t}\right)\right]^{2}\right\}\end{array}$ \\
\hline$\Delta \beta_{z}$ & $\begin{array}{l}0.016529-0.00163 Z_{t}^{2.5}+3.68857 \times 10^{-4} Z_{t}^{3} \\
\quad+1.95822 e^{-Z_{t}}\end{array}$ \\
\hline$\Delta \alpha_{v}$ & $\begin{array}{l}0.04921-0.08217 \mu-0.07588 p^{-1}+5.9372 \times 10^{-3} \mu_{0}^{2} \\
\quad-0.03459 p^{-2}+0.1555 \mu_{0} p^{-1}\end{array}$ \\
\hline$\Delta \beta_{v}$ & $0.0585-0.01972 \sqrt{p} \ln (p)-0.1292 \frac{\ln (p)}{p^{2}}$ \\
\hline
\end{tabular}

total column water vapor $p$. The corrected relationship for cloudy sky (single-layer ice cloud) is given by

$$
\begin{aligned}
& R_{\mathrm{abs}}=\alpha_{0}+\alpha_{\mathrm{icl}}-\left(\beta_{0}+\beta_{\mathrm{icl}}\right) R_{\mathrm{ref}}, \quad \text { and } \\
& \alpha_{\mathrm{icl}}=\Delta \alpha_{d}\left(D_{\mathrm{ge}}, \mu_{0}\right)-\Delta \alpha_{z}\left(Z_{t}, \mu_{0}\right)-\Delta \alpha_{v}\left(p, \mu_{0}\right) \\
& \beta_{\mathrm{icl}}=\Delta \beta_{d}\left(D_{\mathrm{ge}}, \mu_{0}\right)+\Delta \beta_{z}\left(Z_{t}\right)+\Delta \beta_{v}(p) .
\end{aligned}
$$

The terms of the intercept and slope are parameterized and given in Table 5. They were derived from model calculations for a large number of ice cloud sky cases by means of curve fitting. The parameterized equations are fitted for $D_{\text {ge }}$ ranging from 10 to $130 \mu \mathrm{m}$, bearing in mind that the size of ice crystals near the cloud top is usually small. Figure $7 \mathrm{a}$ presents a comparison of error histograms obtained with and without the correction for the effects of $D_{\mathrm{ge}}$. The probabilities of errors are estimated from 13056 ice cloud cases with various $D_{\text {ge }}$, IWC, cloud-top and -bottom height, SZA, surface type and $p$. These clouds are located between 6 and 11 $\mathrm{km}$ over ocean and land surfaces for 16 values of SZA ranging from $1^{\circ}$ to $76^{\circ}$. Here, $D_{\text {ge }}$ ranges from 10 to 130 $\mu \mathrm{m}$ and IWC from 0.01 to $0.08 \mathrm{~g} \mathrm{~m}^{-3}$. They do not include clouds of small $D_{\mathrm{ge}}\left(D_{\mathrm{ge}}<30 \mu \mathrm{m}\right)$ and large IWC (IWC $>0.03 \mathrm{~g} \mathrm{~m}^{-3}$ ), which in reality are rare for ice clouds. The probabilities of errors in the estimates of $F_{\text {abs }}$ are $54.1 \%$ within $\pm 2.5 \mathrm{~W} \mathrm{~m}^{-2}, 94.6 \%$ within $\pm 7.5 \mathrm{~W} \mathrm{~m}^{-2}$, and $97.7 \%$ within $\pm 10 \mathrm{~W} \mathrm{~m}^{-2}$. Errors larger than $\pm 10 \mathrm{~W} \mathrm{~m}^{-2}$ occur for cases having large SZA and small IWC that are over desert surfaces. In comparison, the errors without the correction for $D_{\text {ge }}$ are larger, with a low probability $(12.5 \%)$ of errors within $\pm 10 \mathrm{~W} \mathrm{~m}^{-2}$. This correction is now feasible even with the operational Advanced Very High Resolution Radiometer (AVHRR) that has provided measurements of global coverage at a $1-\mathrm{km}$ nominal resolution for nearly 2 decades. Ou et al. (1999) have demonstrated that use of the two AVHRR channels $(0.63$ and $3.7 \mu \mathrm{m})$ can 

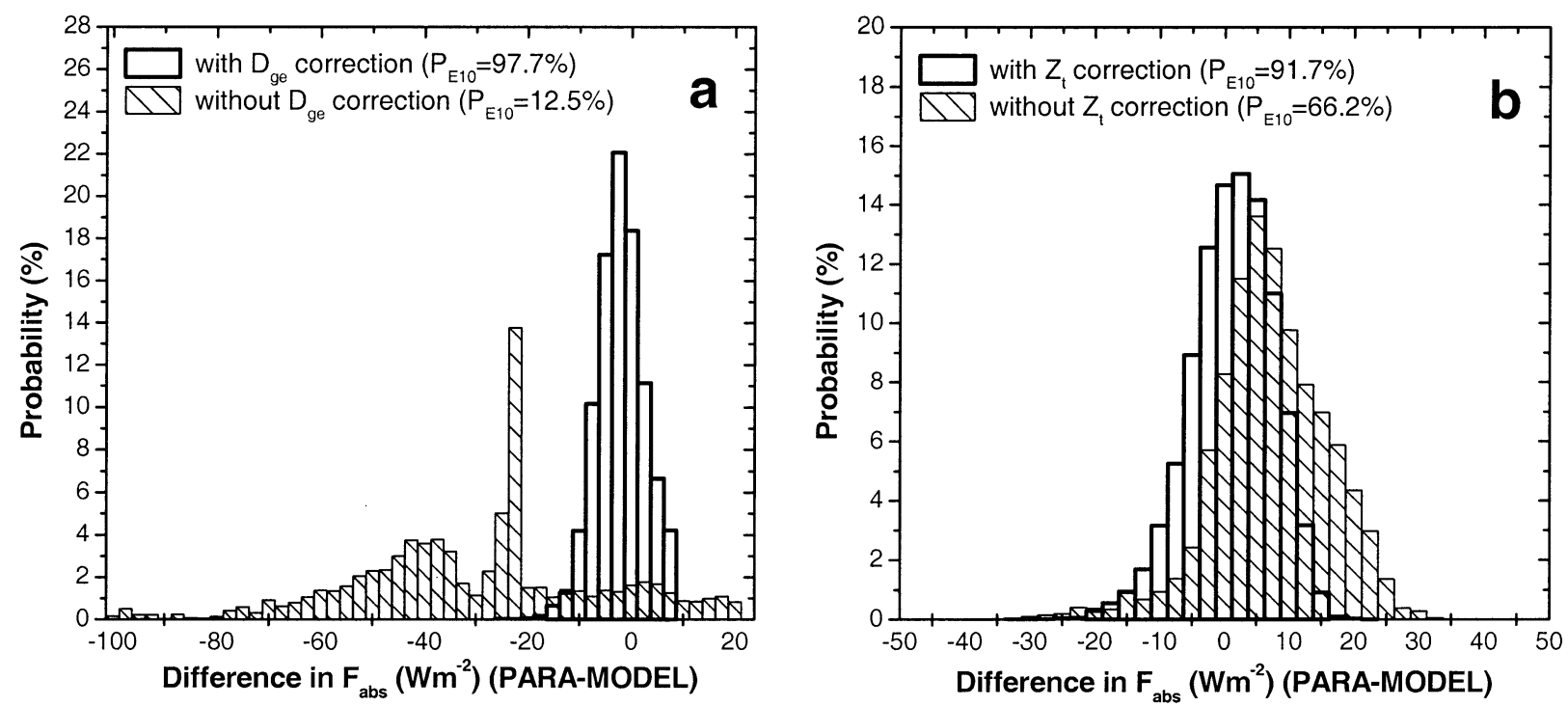

FIG. 7. (a) Probabilities of the error in the SSRB retrieval with and without correction for the effects of $D_{\text {ge }}$. The cloud-top height is fixed at $11 \mathrm{~km}$. (b) Probabilities of the error in the SSRB retrieval with and without the cloud-top correction. Here, $D_{\mathrm{ge}}$ ranges from 10 to 130 $\mu \mathrm{m}$.

retrieve the optical depth and mean effective size of ice crystals.

The corrections to the intercept and slope due to cloud-top height $Z_{t}$ are valid for $Z_{t}$ from 6 to $14 \mathrm{~km}$. The histogram of errors in $F_{\text {abs }}$ with corrections for both cloud top and $D_{\mathrm{ge}}$ is shown in Fig. 7b for ice clouds with its top height varying from 6 to $14 \mathrm{~km}$ and its $D_{\text {ge }}$ varying from 10 to $130 \mu \mathrm{m}$. With the two corrections, the probability of errors falling within $\pm 10 \mathrm{~W} \mathrm{~m}^{-2}$ is $91.7 \%$. The probability of errors in the SSRB without the correction for cloud-top height is also shown. The errors are relatively large and have an overall bias of

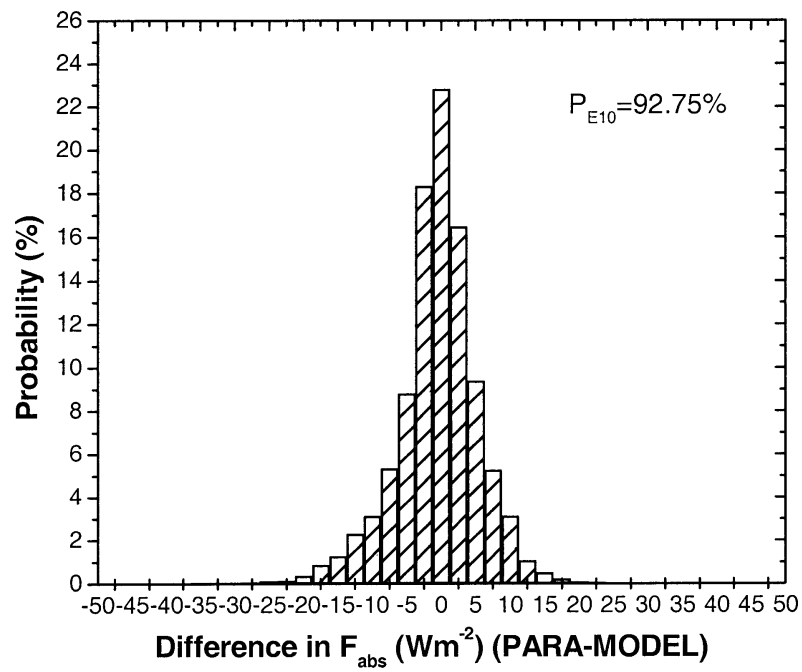

FIG. 8. Probabilities of the errors in the SSRB retrieval for clouds with varying bottom heights (from 5 to $10 \mathrm{~km}$ ) and a fixed $D_{\text {ge }}$ of $60 \mu \mathrm{m}$. about $+5 \mathrm{~W} \mathrm{~m}^{-2}$. The probability of errors within \pm 10 $\mathrm{W} \mathrm{\textrm {m } ^ { - 2 }}$ is only $66.2 \%$.

In contrast, changes in cloud-bottom height have a relatively minor effect. Figure 8 shows the probabilities of errors in $F_{\text {abs }}$ for clouds with varying bottom heights (from 5 to $10 \mathrm{~km}$ ) and a fixed $D_{\mathrm{ge}}$ of $60 \mu \mathrm{m}$. Without any correction for cloud-bottom height, the probability of errors within $10 \mathrm{~W} \mathrm{~m}^{-2}$ is about $92.75 \%$. It confirms that the relationship between $F_{\text {abs }}$ and $F_{\text {ref }}$ is not very sensitive to ice-cloud-bottom height.

Figure 9 shows the histograms of the probability of errors in the SSRB retrieval with and without all corrections for 19298 ice cloud sky cases. They include 66 water vapor profiles, as well as temperature profiles for the model atmospheres of MLS, tropical (TRO), and midlatitude winter (MLW) over a grassland surface. Here, cloud-top (-bottom) height ranges from 6 to 14 $\mathrm{km}$ (from 2 to $13 \mathrm{~km}$ ), particle effective size from 10 to $130 \mu \mathrm{m}$, and SZA from $8^{\circ}$ to $76^{\circ}$. The probability of errors within $\pm 10 \mathrm{~W} \mathrm{~m}^{-2}$ is $91.26 \%$. The probability of errors without the corrections, that is, using only the clear-sky algorithm to retrieve the SSRB, is also given in Fig. 9. They are apparently much larger; the probability of errors within $\pm 10 \mathrm{~W} \mathrm{~m}^{-2}$ in the SSRB retrieved by the original clear-sky algorithm is only $19.35 \%$, with a large systematic bias error of $-9.8 \mathrm{~W} \mathrm{~m}^{-2}$.

It should be stated that the above uncertainty estimation is based entirely on model calculations, assuming that the detailed radiative transfer model (Fu and Liou 1993) and input variables are free from any deficiencies. In other words, the uncertainty is simply a measure of the closeness between the simple inversion algorithm and the detailed complex model, plus additional errors incurred from misinterpretation or misspecification of one or more input 


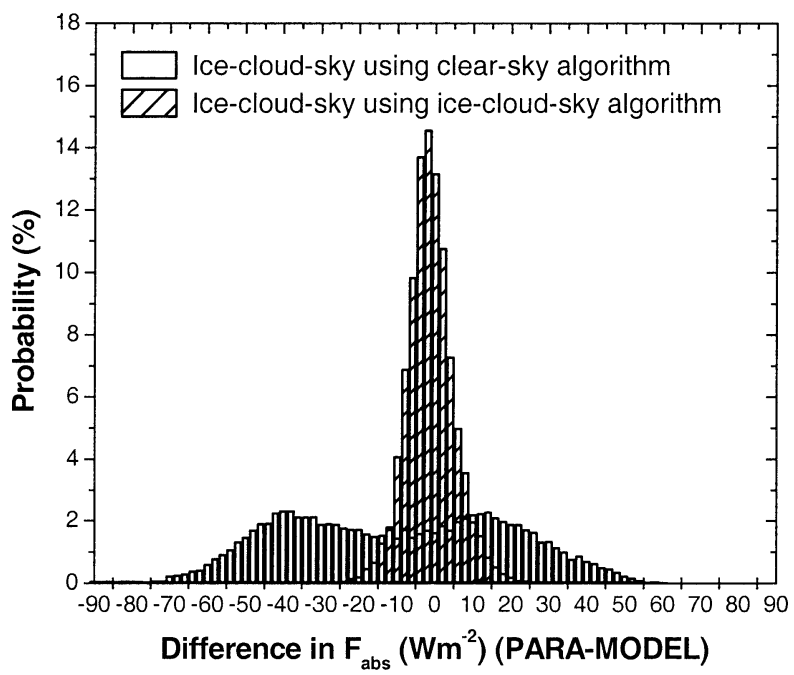

FIG. 9. The probability of errors in the SSRB retrieval with and without ice cloud sky corrections [Eqs. (12)-(18)] for 19298 simulated ice cloud sky cases. The cases involve 66 water vapor profiles contingent upon cloud-top and -bottom height, as well as temperature profiles for the model atmospheres of MLS, TRO, and MLW over a grassland surface. Cloud-top (-bottom) height ranges from 6 to 14 $\mathrm{km}$ (from 2 to $13 \mathrm{~km}$ ), particle effective size from 10 to $140 \mu \mathrm{m}$, and SZA from $8^{\circ}$ to $76^{\circ}$.

variables. Real uncertainties are yet to be assessed with real observational data when all or major input variables become available. Charlock and Alberta (1996) estimated that the range of discrepancies between measured and model-simulated TOA net and surface net fluxes using the Fu and Liou (1993) model. While this could be construed as an uncertainty range for the detailed model, it also compasses errors resulting from inadequate knowledge of the input variables, especially with regard to ice cloud parameters, as well as measurement uncertainties (Dutton et al. 2001). Unfortunately, there is a severe lack of coincident measurements of ice cloud parameters, together with satellite- and ground-based radiation observations, essential to evaluate the true estimation uncertainties.

\section{Summary}

A comprehensive investigation is made of the uncertainties in the retrieval of the surface solar radiation budget (SSRB) under ice cloud conditions; parameterization schemes are developed to correct for the uncertainties. Errors in the retrieval originate from two major sources: the inversion algorithm and input parameters. While we cannot retrieve all ice cloud parameters reliably, significant advancement has been made in the remote sensing of some parameters including the ice effective size (e.g., Ou et al. 1999). More breakthroughs are likely to occur in the near future thanks to the emergence of new-generation satellite sensors such as the 94-GHz radar on CloudSat and MODIS on Terra and Aqua. The 94-GHz radar on CloudSat, for example, will be able to provide, among other quantities, the vertical profiles of ice water content and particle size, as well as the geometrical locations of cloud layers (Stephens et al. 2001). Sensitivities of SSRB to the vertical profile of ice cloud effective size, cloud phase, and multilayered structure are investigated in this work. The findings of the sensitivity studies provide guidance for the development of correction terms introduced to the SSRB retrieval algorithm originally developed by $\mathrm{Li}$ et al. (1993).

The inversion algorithm of $\mathrm{Li}$ et al. (1993) was designed mainly for clear and liquid water cloud conditions. No particular consideration was paid to ice clouds whose optical properties are distinct enough for special treatment. In this study, we have conducted extensive radiative transfer simulations for 1) examining the impact of ice cloud parameters on TOA-and surface solar fluxes, 2) studying the sensitivities of the relationship between the two quantities to various ice cloud parameters in the context of retrieving the SSRB, and 3) the development of parameterization schemes to explicitly account for the influence of those parameters that dictate most of the relationship.

The SSRB retrievals for cloudy skies are sensitive, to a varying degree, to cloud parameters as well as the atmospheric parameters. Among the most sensitive parameters are the particle effective size, cloud-top height, and SZA. The particle effective size has a more significant influence on SSRB than the ice-cloud-top height. For example, errors due to misinterpretation of cloud top are from +30 to $-25 \mathrm{~W} \mathrm{~m}^{-2}$ for the SZA of $30^{\circ}$. However, errors due to misinterpretation of $D_{\mathrm{ge}}$ are from +35 to $-50 \mathrm{~W} \mathrm{~m}^{-2}$. The errors diminish as SZA decreases. The shape of the ice crystal has a nearly negligible effect on the SSRB retrieval. The SSRB retrieved from the TOAreflected flux depends on the vertical profile of ice crystal size, but is influenced primarily by the size near the top layer of a cloud. Treatment of a decreasing profile $(10 \mu \mathrm{m}$ at the top and $100 \mu \mathrm{m}$ at the bottom for a cloud of 1-km cloud) as a constant profile leads a maximal errors of about $+30 \mathrm{~W} \mathrm{~m}^{-2}$ in the SSRB retrieved. Errors in SSRB retrievals due to mistreatment of a multilayered multiphase cloud as a single-layer ice cloud are contingent upon the optical depth of the higher ice cloud and that of water cloud below. Larger errors occur for a thin ice cloud situated above a thick water cloud. However, the errors incurred by treating a multilayered multiphase cloud as a single-layer ice cloud are less than those resulting from treating the ice layer as water clouds.

Based on the results of sensitivity tests, parameterizations are developed as correction terms added to the clear-sky retrieval algorithm of Li et al. (1993) for application under ice cloud conditions. The parameterizations are functions of the effective size of ice cloud crystals, cloud-top height, total water vapor, and SZA. They were derived under a wide range of ice cloud, atmospheric conditions (MLS, MLW, and TRO), and surface conditions (various land and ocean surfaces). Here, $D_{\text {ge }}$ ranges from 10 to $130 \mu \mathrm{m}$; cloud-top height 
from 6 to $14 \mathrm{~km}$; cloud-bottom height from 5 to $13 \mathrm{~km}$ (maximum cloud thickness of $6 \mathrm{~km}$ ); and SZA from $1^{\circ}$ to $76^{\circ}$. For $91 \%$ of the ensembled cases, the revised algorithm can estimate SSRB to within $\pm 10 \mathrm{~W} \mathrm{~m}^{-2}$ relative to those simulated by detailed radiative transfer models, a significant improvement relative to the use of the clear-sky algorithm. The probability of the same error range $\left( \pm 10 \mathrm{~W} \mathrm{~m}^{-2}\right)$ falls to $55 \%$ if the correction is applied to water clouds, implying that different corrections should be applied for water clouds, as proposed by Masuda et al. (1995).

Acknowledgments. We are grateful to Dr. Q. Fu for consultation and use of his code. The study was supported by the U.S. Department of Energy Grant DEFG02-01ER63166 under the Atmospheric Radiation Measurement (ARM) program.

\section{REFERENCES}

Auer, A. H., Jr., and D. L. Veal, 1970: The dimension of ice crystals in natural clouds. J. Atmos. Sci., 27, 919-926.

Augustine, J. A., J. J. DeLuisi, and C. N. Long, 2000: SURFRADA national surface radiation budget network for atmospheric research. Bull. Amer. Meteor. Soc., 81, 2341-2358.

Barker, H. W., and Z. Li, 1995: Improved simulation of clear-sky shortwave radiative transfer in the CCC GCM. J. Climate, 8, 2213-2223.

Bishop, J. K., and W. B. Rossow, 1991: Spatial and temporal variability of global surface solar irradiance. J. Geophys. Res., 96, $16839-16858$.

Briegleb, B. P., P. Minnis, V. Ramanathan, and E. Harrison, 1986: Comparison of regional clear-sky albedos inferred from satellite observations and model computations. J. Climate Appl. Meteor., 25, 214-226.

Charlock, T., and T. L. Alberta, 1996: The CERES/ARM/GEWEX experiment (CAGEX) for the retrieval of radiative fluxes with satellite data. Bull. Amer. Meteor. Soc., 77, 2673-2683.

Chou, M.-D., and W. Zhao, 1997: Estimation and model validation of surface solar radiation and cloud radiative forcing using TOGA COARE measurements. J. Climate, 10, 610-620.

—, A. Arking, J. Otterman, and W. L. Ridgway, 1995: The effect of clouds on atmospheric absorption of solar radiation. Geophys. Res. Lett., 22, 1885-1888.

Conant, W. C., V. Ramanathan, F. P. J. Valero, and J. Meywerk, 1997: An examination of the clear-sky solar absorption over the central equatorial Pacific: Observations versus models. J. Climate, 10, $1874-1884$.

Dutton, E. G., J. Michalsky, T. Stoffel, B. W. Forgan, J. Hickey, D. W. Nelson, T. L. Alberta, and I. Reda, 2001: Measurement of broadband diffuse solar irradiance using current commercial instrumentation with a correction for thermal offset errors. J. Atmos. Oceanic Technol., 18, 297-314.

Fowler, L. D., and D. A. Randall, 1996: Liquid and ice cloud microphysics in the CSU general circulation model. Part II: Impact on cloudiness, the earth's radiation budget, and the general circulation of the atmosphere. J. Climate, 9, 530-560.

Fu, Q., 1996: An accurate parameterization of the solar radiative properties of cirrus clouds for climate models. J. Climate, 9, 2058-2082.

— , and K. N. Liou, 1993: Parameterization of the radiative properties of cirrus clouds. J. Atmos. Sci., 50, 2008-2025.

Gautier, C., G. Diak, and S. Masse, 1980: A simple physical model to estimate incident solar radiation at the surface from GOES satellite data. J. Appl. Meteor., 19, 1005-1012.

Heymsfield, A. J., 1977: Precipitation development in stratiform ice clouds: A microphysical and dynamical study. J. Atmos. Sci., 34, 367-381.

— size spectrum of ice clouds in terms of the ambient temperature and the ice water content. J. Atmos. Sci., 41, 846-855.

— , L. M. Miloshevich, G. M. McFarquhar, and S. M. Aulenbach, 1998: Nonspherical ice particles in cirrus clouds. Proc. Conf. on Light Scattering by Nonspherical Particles, New York, NY, 36-39.

Li, Z., 1998: Influence of absorbing aerosols on the inference of solar surface radiation budget and cloud absorption. J. Climate, 11, $5-17$.

—_ and H. G. Leighton, 1993: Global climatologies of solar radiation budgets at the surface and in the atmosphere from 5 years of ERBE data. J. Geophys. Res., 98, 4919-4930.

- _ _ , K. Masuda, and T. Takashima, 1993: Estimation of SW flux absorbed at the surface from TOA reflected flux. J. Climate, 6, 318-330.

— T. Charlock, and C. Whitlock, 1995: Assessment of the global monthly mean surface insolation estimated from satellite measurements using global energy balance archive data. J. Climate, 8, 315-328.

— L. Loreau, and A. Arking, 1997: On solar energy disposition: A perspective from observation and modeling. Bull. Amer. Meteor. Soc., 78, 53-70.

Liou, K. N., 1992: Radiation and Cloud Processes in the Atmosphere. Oxford University Press, $490 \mathrm{pp}$.

—_ and R. H. Coleman, 1980: Light scattering by hexagonal columns and plates. Light Scattering by Irregularly Shaped Particles, D. W. Schuerman, Ed., Plenum Press, 207-218.

Macke, A., J. Mueller, and E. Raschke, 1996: Single scattering properties of atmospheric ice crystals. J. Atmos. Sci., 53, 2813-2825.

_ _ P. N. Francis, G. M. McFarquhar, and S. Kinne, 1998: The role of ice particle shapes and size distributions in the single scattering properties of cirrus clouds. J. Atmos. Sci., 55, 2874-2883.

Masuda, K., H. G. Leighton, and Z. Li, 1995: A new parameterization for the determination of solar flux absorbed at the surface from satellite measurements. J. Climate, 8, 1615-1629.

Mishchenko, M. I., W. B. Rossow, A. Macke, and A. A. Lacis, 1996 Sensitivity of cirrus cloud albedo, bidirectional reflectance and optical thickness retrieval accuracy to ice particle shape. J. Geophys. Res., 101, 16 973-16 985.

Ohmura, A., and Coauthors, 1998: Baseline Surface Radiation Network (BSRN/WCRP): New precision radiometry for climate research. Bull. Amer. Meteor. Soc., 79, 2115-2136.

Ou, S. C., K. N. Liou, M. D. King, and S. C. Tsay, 1999: Remote sensing of cirrus cloud parameters based on $0.63-3.7 \mathrm{~mm}$ radiance correlation technique applied to AVHRR data. Geophys. Res. Lett., 26, 2437-2440.

Pinker, R. T., and I. Laszlo, 1992: Modeling surface solar irradiance for satellite applications on a global scale. J. Appl. Meteor., 31, 194-211.

_ , R. Frouin, and Z. Li, 1995: A review of satellite methods to derive surface shortwave irradiance. Remote Sens. Environ., 51, $108-124$

Ramanathan, V., B. Subasilar, G. J. Zhang, W. Conant, R. D. Cess, J. T. Kiehl, H. Grassl, and L. Shi, 1995: Warm pool heat budget and shortwave cloud forcing: A missing physics. Science, 267, 499-503.

Randall, D. A., Harshvardhan, D. A. Dazlich, and T. G. Corsetti, 1989: Interactions among radiation, convection, and large-scale dynamics in a general circulation model. J. Atmos. Sci., 46, 1943-1970.

Schmetz, J., 1993: Relationship between solar net radiative fluxes at the top of the atmosphere and at the surface. J. Atmos. Sci., 50, $1122-1132$.

Stephens, G. L., and T. J. Greenwald, 1991: The earth's radiation budget and its relation to atmospheric hydrology. 2. Observations of cloud effects. J. Geophys. Res., 96, 15 325-15 340. , and Coauthors, 2001: The CloudSat mission and the EOS con- 
stellation: A new dimension to space-based observations of clouds and precipitation. Bull. Amer. Meteor. Soc., in press.

Stokes, G. M., and S. E. Schwartz, 1994: The Atmospheric Radiation Measurement (ARM) program: Programmatic background and design of the cloud and radiation test bed. Bull. Amer. Meteor. Soc., 75, 1201-1221.

Waliser, D. E., W. D. Collins, and S. P. Anderson, 1996: An estimate of the surface shortwave cloud forcing over the western Pacific during TOGA COARE. Geophys. Res. Lett., 23, 519-522.

Ward, D. M., 1995: Comparison of the surface solar radiation budget derived from satellite data with that simulated by the NCAR GCM2. J. Climate, 8, 2824-2842.

Whitlock, C. H., and Coauthors, 1995: First global WCRP shortwave surface radiation budget dataset. Bull. Amer. Meteor. Soc., 76, 905-922.
Wielicki, B. A., B. R. Barkstrom, E. F. Harrison, R. B. Lee III, G. L. Smith, and J. E. Cooper, 1996: Clouds and the Earth's Radiant Energy System (CERES): An Earth Observing System experiment. Bull. Amer. Meteor. Soc., 77, 853-868.

Wild, M., A. Ohmura, H. Gilgen, and E. Roeckner, 1995: Validation of general circulation model radiation fluxes using surface observations. J. Climate, 8, 1309-1324.

Zhang, Y., A. Macke, and F. Albers, 1999: Effect of crystal size spectrum and crystal shape on stratiform cirrus radiative forcing. Atmos. Res., 52, 59-75.

Zhang, Y.-C., and W. B. Rossow, 1995: Calculation of surface and top of atmosphere radiative fluxes from physical quantities based on ISCCP data sets. 1. Method and sensitivity to input data uncertainties. J. Geophys. Res., 100, 1149-1165. 